\title{
Relationship between fish and jellyfish as a function of eutrophication and water clarity
}

\author{
Matilda Haraldsson ${ }^{1}$, Kajsa Tönnesson ${ }^{1}$, Peter Tiselius ${ }^{1}$, Tron Frede Thingstad ${ }^{2}$, \\ Dag L. Aksnes ${ }^{2, *}$
}

${ }^{1}$ Department of Biological and Environmental Sciences, University of Gothenburg, Sweden

${ }^{2}$ Department of Biology, University of Bergen, 5020 Bergen, Norway

\begin{abstract}
There is a concern that blooms of cnidarians and ctenophores, often referred to as jellyfish, are increasing in frequency and intensity worldwide and that there is a shift from fish- to jellyfish-dominated systems. We present an idealized analysis of the competitive relationship between zooplanktivorous jellyfish that is based on a generic model, termed 'Killing the Winner' (KtW), for the coexistence of 2 groups utilizing the same resource. Tactile predation by jellyfish makes them less dependent on water optics than fish using vision, and we modified the KtW model to account for this particular trait difference. Expectations of the model are illustrated by use of observations from the Baltic Sea. The model predicts a general succession on how mass of the system distributes when going from an oligotrophic to a eutrophic system. Initially the mass of the system accumulates at the level of the common resource (zooplankton) and planktivorous fish (sprat/herring). At one point, with increased eutrophication, mass starts to accumulate at the level of the top predator (cod) and at a later point, at the level of the jellyfish. For those organisms utilizing vision (fishes) an optimal degree of eutrophication and water clarity is predicted due to a 2-sided effect of eutrophication.
\end{abstract}

KEY WORDS: Jellyfish · Fish · Competition · Killing the winner · Eutrophication · Water clarity

\section{INTRODUCTION}

Blooms of jellyfish, often referring to pelagic cnidarians and ctenophores, have received increased attention in recent years. Although disputed (Condon et al. 2012), there appears to be a trend towards more frequent blooms, higher abundances, and wider geographical distributions (Richardson et al. 2009, Brotz et al. 2012, Purcell 2012). Jellyfish mass occurrence and apparent shifts from fish- to jellyfish-dominated systems have been linked to numerous factors such as fisheries (Brodeur et al. 2002, Lynam et al. 2006, Daskalov et al. 2007), aquaculture (Lo et al. 2008), eutrophication (Parsons \& Lalli 2002, Purcell et al. 2007), hypoxia (Decker et al. 2004, Thuesen et al. 2005), and water clarity (Aksnes 2007, Sørnes et al. 2007). Furthermore, increased jellyfish abundances have been linked to climate change, including temperature increase (Purcell et al. 2007, Lynam et al. 2011), enhanced stratification (Richardson et al. 2009), and decreased $\mathrm{pH}$ (Richardson \& Gibbons 2008). Finally, translocations of species, sometimes referred to as invasions of alien species, have also been seen as contributors to jellyfish blooms (Graham \& Bayha 2007).

The fact that jellyfish blooms have been linked to many factors is not surprising since cnidarians and ctenophores are diverse species groups with a variety of life histories and environmental responses. Thus case-specific analyses and models (e.g. Sørnes et al. 2007, Oguz et al. 2008, Dupont \& Aksnes 2010, Ruiz et al. 2012) are undoubtedly needed to account accurately for observed phenomena. Nevertheless, we present an idealized analysis of the competitive 
relationship between fish and jellyfish that might apply to certain circumstances. We start out with a generic model of coexistence between 2 groups of organisms that compete for the same resource (Fig. 1). This generic model, which is denoted 'Killing the Winner' (KtW; Thingstad et al. 2010), contains a structure wherein a competition specialist is in play with a predator while the other competitor, the defense specialist, is not (Fig. 1). The equilibrium solution of the KtW provides general predictions on how the system responds to changes in the total mass of limiting nutrients of the system, i.e. the degree of eutrophication (Thingstad et al. 2010). Most KtW applications have been on microbial systems (Winter et al. 2010) that are stimulated by increased nutrient

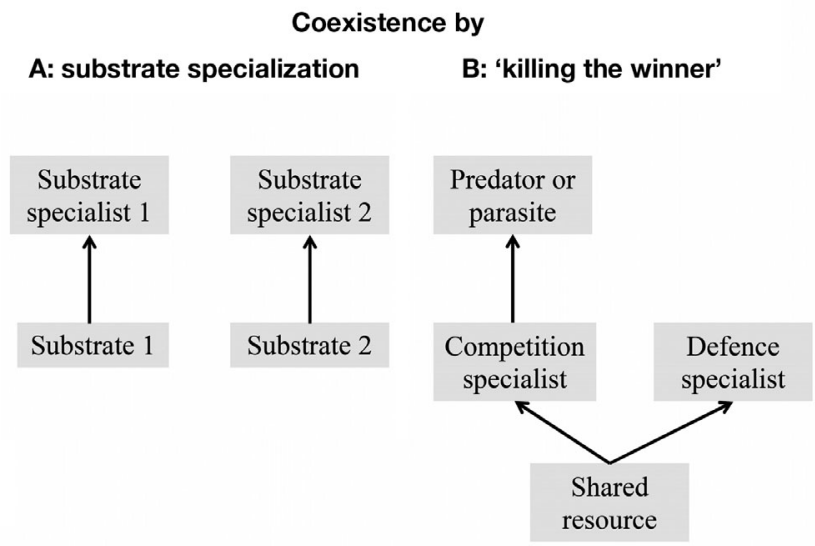

Fig. 1. Two generic principles of coexistence. (A) Coexistence is possible due to specialization for different substrates. (B) The same limiting resource is shared, but a selective loss mechanism prevents the competition specialist from sequestering all of the limiting resource, leaving a niche for the defense specialist (after Thingstad et al. 2010) availability. Important aspects of the habitat of many fishes, such as water clarity and visibility (Eggers 1977, Lester et al. 2004, Aksnes 2007), however, tend to deteriorate at high degrees of eutrophication, and we modified the model to account for such habitat deterioration. We apply data from the Baltic Sea to illustrate KtW predictions on how eutrophication and water clarity affects the competitive relationship between fish and jellyfish. We do not consider this application as a definitive test or validation (sensu Loehle 1983) of the model, but rather use the transparency and analytical tractability offered by the KtW simplification to gain general insights in jellyfish systems that might comply with the assumptions of the KtW structure.

\section{MATERIALS AND METHODS}

\section{Baltic Sea}

The Baltic Sea, which we have used to estimate coefficients of the model and to illustrate KtW predictions, is a complex ecosystem that has experienced extensive changes during the last century. These changes involve eutrophication, reduced water clarity, and increased fishery, among other factors (Table 1). Nutrient inputs have increased (Struck et al. 2000, Savchuk et al. 2008), and the Baltic Sea has turned from an oligotrophic to a eutrophic state (Meier et al. 2011). A low fish biomass during the first part of the 1900s has been indicated due to a lower productivity prior to eutrophication (Thurow 1997). The increased primary production has caused hypoxia (Diaz \& Rosenberg 2008, Savchuk et al. 2008)

Table 1. Some major environmental changes in the Baltic Sea during the last century. SST: sea surface temperature

\begin{tabular}{|llll|}
\hline $\begin{array}{l}\text { Environmental } \\
\text { variable }\end{array}$ & Change & Time period & Source \\
\hline $\begin{array}{l}\text { Eutrophication } \\
\text { Phytoplankton }\end{array}$ & Increase & $1850-2000$ & Struck et al. (2000) \\
& Increase (doubling & $1905 / 06,1912 / 13$ & Wasmund et al. (2008) \\
Hypoxia & over the century) & $1949 / 50$, and 2001-03 & \\
Water clarity & Increase & $1960 \mathrm{~s}$ & Diaz \& Rosenberg (2008) \\
Pollutants & Reduced 0.05 m yr ${ }^{-1}$ & $1919-39,1969-91$ & Sanden \& Håkansson (1996) \\
SST & Increase & $1960 \mathrm{~s}$ & Elmgren (2001) \\
& & & Mackenzie \& Schiedek (2007) \\
& Increase & $1870-2003$ & Fonselius \& Valderrama (2003) \\
Non-indigenous & Increase & $1900-2000$ & Belkin (2009) \\
species & $1.35^{\circ} \mathrm{C}$ increase & $1982-2006$ & Leppäkoski et al. (2002) \\
\hline
\end{tabular}


and has reduced the water clarity (Sanden \& Håkansson 1996, Fleming-Lehtinen \& Laamanen 2012). Despite efforts to reduce nutrient inputs, eutrophication symptoms persist (Backer \& Leppanen 2008, Andersen et al. 2011) and water clarity remains low (Fleming-Lehtinen \& Laamanen 2012). Over the last $100 \mathrm{yr}$, phytoplankton biomass has doubled (Wasmund et al. 2008), phytoplankton composition has changed (Wasmund et al. 2008, Olli et al. 2011), and cyanobacterial blooms have been more frequent (Finni et al. 2001).

The commercial fishery in the Baltic Sea, dominated by cod, sprat, and herring, also increased during the 1900s (Mackenzie et al. 2007). The maximum cod biomass was reported for the early 1980s (Alheit et al. 2005). While fishing pressure increased during the mid-20th century (Mackenzie et al. 2007), the cod biomass decreased 10-fold by the end of the 1980s, shifting the Baltic from a cod-dominated to a spratdominated system (Casini et al. 2009).

The recent appearance of Mnemiopsis leidyi in the North Sea (Faasse \& Bayha 2006), Kattegat area (Tendal et al. 2007), as well as in the Baltic Sea (Javidpour et al. 2006) has raised concerns about an increased likelihood for future gelatinous mass occurrences. Aurelia aurita is presently the dominant jellyfish of the Baltic Sea (Möller 1980, Barz \& Hirche 2005, Haraldsson \& Hansson 2011), which corresponds to the Black Sea situation before the M. leidyi mass occurrences in the 1980s (Weisse \& Gomoiu 2000 and references therein). Cyanea capillata is the second-most abundant jellyfish in the Baltic, although 1 order of magnitude lower than A. aurita.

\section{KtW model for the jellyfish-fish system}

We consider a KtW structure (Figs. 1 \& 2) where zooplanktivorous jellyfish $(J)$ and fish $(F)$ share a common zooplankton $(Z)$ resource, and where the zooplanktivorous fish are exposed to a top predator $(C)$. This structure frames the zooplanktivorous jellyfish and fish as the defense and the competition specialist, respectively. We use Baltic Sea observations on Aurelia aurita and Cyanea capillata (Table 2) to represent the jellyfish biomass and sprat together with herring (Table 2) to show the biomass of the competitor. Cod is a predator of sprat and herring (Sparholt 1994, Casini et al. 2008) and is given the role as the top predator (Fig. 2, Table 2).

In KtW theory, which has primarily been applied to microbial systems (Winter et al. 2010), a quantity that corresponds to the total amount of a limiting nutrient

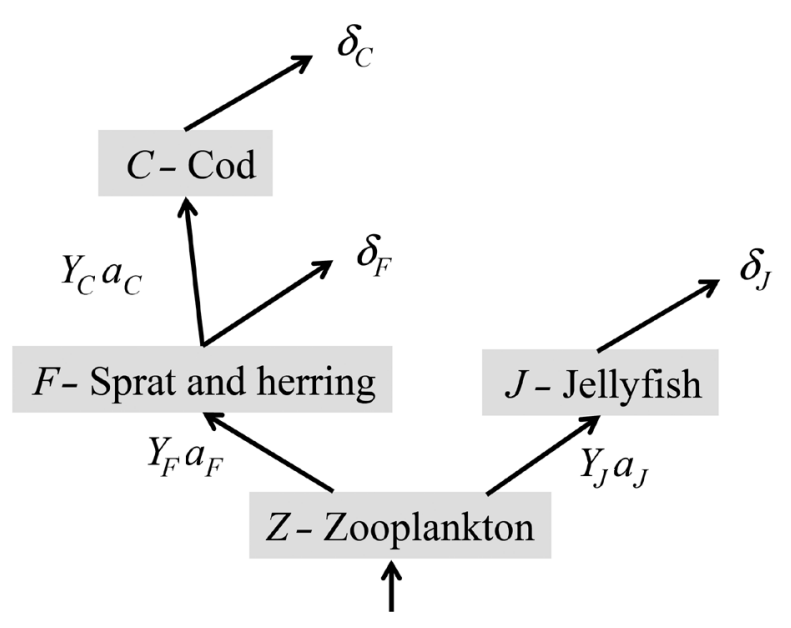

Fig. 2. 'Killing the Winner' model for coexistence between jellyfish and zooplanktivorous fish (sprat and herring) in the Baltic Sea. Fishery mortality is included in the loss rates $\delta_{C}$ and $\delta_{F}$, while the degree of eutrophication of the system is represented by the amount of mass that enters the system through zooplankton (see 'Materials and methods'). $a$ and $Y$ represent the predation coefficients and the transfer efficiencies (yields) between 2 trophic levels, respectively; e.g. $a_{C}$ is the specific predation rate of $\operatorname{cod}(C)$ on sprat and herring $(F)$ so that the product $a_{C} F C$ is the amount of sprat and herring that is removed by cod per unit time (see Eq. 1c). In order to convert this amount to cod biomass, a yield, $Y_{C_{r}}$ is applied (see Eq. 1d)

(also including the mass of the organisms), such as phosphorus, represents the degree of eutrophication of the system (Thingstad et al. 2010). In our highertrophy system, we use carbon $(\mathrm{C})$, rather than a mineral nutrient, as currency, and we will assume that the biomass of our idealized system is constrained by the mass flowing through the zooplankton $\left(P_{Z,}, \mathrm{C}\right.$ $\mathrm{yr}^{-1}$ ). In the Baltic Sea application, we let this mass reflect the primary production, $P_{P_{1}}$ according to $P_{Z}=$ $T_{Z} P_{P}$ where $T_{Z}$ corresponds to the transfer efficiency between primary and secondary production. Both $P_{Z}$ and $P_{P}$ will be used as indices of the degree of eutrophication.

According to Fig. 2, we specify the equations:

$$
\begin{gathered}
\frac{d Z}{d t}=P_{Z}-a_{F} Z F-a_{J} Z J \\
\frac{d J}{d t}=Y_{J} a_{j} Z J-\delta_{j} J \\
\frac{d F}{d t}=Y_{F} a_{F} Z F-a_{C} C F-\delta_{F} F \\
\frac{d C}{d t}=Y_{C} a_{C} F C-\delta_{C} C
\end{gathered}
$$


Table 2. Biomasses (Mt) in the Baltic Sea used to estimate model coefficients. Means \pm SD for the period 2000 to 2009 (except zooplankton: 2000 to 2006); jellyfish values are the average of sampling conducted in the Bornholm basin in September 2002 and 2009 (20.5 and 99.5 Mt wet weight, WW, respectively). Loss rates for the fish groups represent catch or biomass, with an assumed natural mortality of $0.2 \mathrm{yr}^{-1}$ for cod and $0.1 \mathrm{yr}^{-1}$ for sprat and herring (the latter excludes cod predation, which is represented in the model). Loss rate for jellyfish corresponds to a mortality of $1 \% \mathrm{~d}^{-1}$. We used the combined area of the Baltic Proper and the Gulf of Finland $\left(258310 \mathrm{~km}^{2}\right)$ and assumed a vertical layer of $50 \mathrm{~m}$ in the conversion of zooplankton and jellyfish to total biomasses from abundances specified per $\mathrm{m}^{3}$. ${ }^{\mathrm{a}}$ Conversion from WW to carbon $(\mathrm{C})$ with the factors $0.06(\mathrm{C}=$ $0.5 \mathrm{DW}, \mathrm{DW}=0.12 \mathrm{WW}$; Parsons et al. 1992) for zooplankton, 0.1 for fish (Arrhenius \& Hansson 1993), and 0.001 (C = $0.05 \mathrm{DW}$,

DW $=0.02 \mathrm{WW}$; Schneider 1988) for jellyfish

\begin{tabular}{|c|c|c|c|c|c|}
\hline \multirow[t]{2}{*}{ Group } & \multicolumn{2}{|c|}{$\smile$ Biomass } & \multirow{2}{*}{$\begin{array}{c}\text { Landing } \\
\mathrm{WW} \mathrm{yr}^{-1} \pm \mathrm{SD}\end{array}$} & \multirow{2}{*}{$\begin{array}{c}\text { Loss rate }(\delta) \\
\mathrm{yr}^{-1}\end{array}$} & \multirow[t]{2}{*}{ Source } \\
\hline & $\mathrm{WW} \pm \mathrm{SD}$ & Carbon $^{\mathrm{a}}$ & & & \\
\hline Zooplankton (Z) & $3.7 \pm 1.0$ & 0.220 & & & Casini et al. (2008) \\
\hline Jellyfish $(J)$ & $60.8 \pm 54.8$ & 0.061 & & 3.6 & $\begin{array}{l}\text { Barz \& Hirche (2005), } \\
\text { Haraldsson \& Hansson (2011) }\end{array}$ \\
\hline Sprat and herring $(F)$ & $2.395 \pm 0.227$ & 0.240 & $0.493 \pm 0.040$ & 0.31 & \\
\hline $\operatorname{Cod}(C)$ & $0.215 \pm 0.053$ & 0.022 & $0.087 \pm 0.022$ & 0.60 & $\begin{array}{l}\text { Swedish Agency for Marine and } \\
\text { Water Management (2010) }\end{array}$ \\
\hline
\end{tabular}

where $Z, J, F$, and $C$ are expressed in units of total biomass ( $\mathrm{g} \mathrm{C}$ ) of the system. Solving for steady state yields the equilibrium biomasses:

$$
\begin{gathered}
Z^{*}=\frac{\delta_{J}}{Y_{J} a_{J}} \\
J^{*}=\frac{Y_{J}}{\delta_{J}} P_{Z}-\frac{a_{F}}{Y_{C} a_{C} a_{J}} \delta_{C} \\
F^{*}=\frac{\delta_{C}}{Y_{C} a_{C}} \\
C^{*}=a_{C}^{-1}\left(\frac{Y_{F}}{Y_{J}} \frac{a_{F}}{a_{J}} \delta_{J}-\delta_{F}\right)
\end{gathered}
$$

From Eq. (2b), we see that jellyfish existence (i.e. positive values of $J^{*}$ ) requires that the degree of eutrophication exceeds a threshold value:

$$
P_{Z}>\frac{a_{F}}{Y_{C} Y_{J} a_{C} a_{J}} \delta_{C} \delta_{J}
$$

For $P_{Z}$ less than this quantity, we eliminate jellyfish, and the system of equations reduces to:

$$
\begin{gathered}
\frac{d Z}{d t}=P_{Z}-a_{F} Z F \\
\frac{d F}{d t}=Y_{F} a_{F} Z F-a_{C} C F-\delta_{F} F \\
\frac{d C}{d t}=Y_{C} a_{C} F C-\delta_{C} C
\end{gathered}
$$

which has the steady-state solution:

$$
\begin{gathered}
Z^{*}=\frac{Y_{C}}{\delta_{C}} \frac{a_{C}}{a_{F}} P_{Z} \\
F^{*}=\frac{\delta_{C}}{Y_{C} a_{C}} \\
C^{*}=a_{C}^{-1}\left(Y_{F} Y_{C} \frac{a_{C}}{\delta_{C}} P_{Z}-\delta_{F}\right)
\end{gathered}
$$

From Eq. (5c), we see that cod existence (i.e. positive values of $C^{*}$ ) requires that $P_{Z}$ must exceed the threshold:

$$
P_{Z}>\frac{\delta_{F} \delta_{C}}{Y_{F} Y_{C} a_{C}}
$$

For $P_{Z}$ less than this quantity, the system of equations reduces to

$$
\frac{d Z}{d t}=P_{Z}-a_{F} Z F
$$

$$
\frac{d F}{d t}=Y_{F} a_{F} Z F-\delta_{F} F
$$

which has the steady-state solution

$$
\begin{gathered}
Z^{*}=\frac{\delta_{F}}{Y_{F} a_{F}} \\
F^{*}=\frac{Y_{F}}{\delta_{F}} P_{Z}
\end{gathered}
$$




\section{Modified KtW model for the jellyfish-fish system}

In the above model, increased eutrophication implies higher production and more zooplankton available for fish and jellyfish, but essentially assumes that there are no negative effects from eutrophication on the habitats of the organisms. While most jellyfish are tactile predators (Sørnes \& Aksnes 2004, Acuña et al. 2011), many fishes are visual predators that are affected by water clarity and visibility (Eggers 1977, Lester et al. 2004, Aksnes 2007), which tend to deteriorate with increased eutrophication. Thus we now assume that the habitats of the fishes decline with increased eutrophication, while the habitats of zooplankton and jellyfish are unaffected.

We express the habitat volumes of the 4 biomass groups; $V_{x}=A H_{x}$ where $A\left(\mathrm{~m}^{2}\right)$ corresponds to the combined area of the Baltic Proper and the Gulf of Finland $\left(258310 \mathrm{~km}^{2}\right)$ and $H_{x}(\mathrm{~m})$ is the vertical extension of the habitat of biomass group $x$. The system of equations, with this explicit representation of habitat volumes, is given in Appendix 1.

We assume that the extensions of the vertical habitats, $H_{X}$ of the 2 fish groups are constrained by water clarity according to (Aksnes 2007): $H_{x} \propto(c+K)^{-1}$, where $c\left(\mathrm{~m}^{-1}\right)$ is the beam (or image) attenuation coefficient, and $K\left(\mathrm{~m}^{-1}\right)$ is the attenuation of downwelling irradiance. Both are key properties for underwater vision (Johnsen 2012) and visual feeding (Eggers 1977, Aksnes \& Utne 1997), where $C$ determines the maximal sighting distance of a visual predator, and $K$ determines the light intensity at depth. In practice, different $c$ and $K$ values apply to different wavelengths, but here we assume that the 2 quantities are properties of all wavelengths relevant for the actual visual system.

Fortunately, the widely monitored Secchi disk depth $(S ; \mathrm{m})$ does, like $H_{x \prime}$ relate inversely to $c$ and $K$, i.e. $S \propto(C+K)^{-1}$ (Preisendorfer 1986). Thus we have, $H_{X} \propto S$, which means that changes in Secchi disk depth might serve as proxy for changes in the extension of the vertical vision based habitat of the fishes (Aksnes 2007), and we make us of this proxy below.

\section{Estimates of model coefficients}

\section{KtW model}

Table 2 summarizes the values of the biomasses and loss rates that we have used to characterize the current Baltic Sea. Insertion of these values into the steady-state equations (Eq. 2a-d) provided estimates of the predation coefficients and the degree of eutrophication (Table 3). The estimate of $P_{Z}$ is $16.5 \mathrm{~g} \mathrm{C} \mathrm{m}^{-2} \mathrm{yr}^{-1}$. According to Wasmund et al. (2001, their Table 5), the average primary production $\left(P_{P}\right)$ for the Baltic Proper and the Gulf of Finland corresponds to $187 \mathrm{~g} \mathrm{C} \mathrm{m}^{-2} \mathrm{yr}^{-1}$. These estimates indicate a transfer efficiency between primary and secondary production, $T_{Z}=16.5 / 187=0.09$.

\section{Modified KtW model}

Here we need a relationship on how the vertical habitat $\left(H_{x}\right)$ is affected by eutrophication (i.e. by primary production), and in order to establish this relationship, some assumptions are required. First, we assume that a hypothetical water column, which is devoid of phytoplankton (and consequently of primary production), imposes no visual constraints on the fishes. For this case, we consider the habitats of zooplankton, jellies, and fishes to be equal (as also implied in the basic KtW model). Second, as primary production increases, we assume that the visual constraints of the fishes also increase because water clarity deteriorates with increasing phytoplankton density.

Below we have approximated that if there were no primary production (i.e. no chlorophyll), the Baltic Sea Secchi depth would have been twice (10 to $15 \mathrm{~m}$ ) of what is observed, i.e. $\sim 6 \mathrm{~m}$ (Fleming-Lehtinen \& Laamanen 2012). To represent current primary production, we apply $187 \mathrm{~g} \mathrm{C} \mathrm{m}^{-2} \mathrm{yr}^{-1}$ (Wasmund et al. 2001), and interpolation then suggests a $2.7 \%$ decrease in Secchi depth $(S)$ for each $10 \mathrm{~g} \mathrm{C} \mathrm{m}^{-2} \mathrm{yr}^{-1}$ rise in primary production. According to the proxy, $H_{x} \propto S$, explained above, we also used this value to represent the loss of fish habitat as a function of primary production.

Table 3. Predation coefficients ( $a$ in Fig. 2) of the basic 'Killing the Winner' model. These estimates were obtained by solving for steady state (Eq. 2) by insertion of the total biomasses and the loss rate estimates in Table 2 and assuming all yields ( $Y^{\prime}$ s) equal to 0.1

\begin{tabular}{|lcrc|}
\hline & Symbol & Estimate & Unit \\
\hline Mass entering zooplankton $(Z)$ & $P_{Z}$ & 4.3 & $\mathrm{Mt} \mathrm{C} \mathrm{yr}^{-1}$ \\
Expressed per surface area & & 16.5 & $\mathrm{~g} \mathrm{C} \mathrm{m}^{-2} \mathrm{yr}^{-1}$ \\
Predation coefficient of & & & \\
jellyfish $(J)$ & $a_{J}$ & 163.6 & $(\mathrm{Mt} \mathrm{C})^{-1} \mathrm{yr}^{-1}$ \\
sprat and herring $(F)$ & $a_{F}$ & 39.1 & $(\mathrm{Mt} \mathrm{C})^{-1} \mathrm{yr}^{-1}$ \\
cod $(C)$ & $a_{C}$ & 25.0 & $(\mathrm{Mt} \mathrm{C})^{-1} \mathrm{yr}^{-1}$ \\
\hline
\end{tabular}


Insertion of the values of the biomasses and the loss rates (Table 2) into the modified KtW equations (see Appendix 1) provided estimates of the predation coefficients and the current degree of eutrophication (Table 4). Note that the unit of the predation coefficients is different from that in Table 3 , which is due to the introduction of habitat volumes. The estimate of $P_{Z}\left(34.7 \mathrm{~g} \mathrm{C} \mathrm{m}^{-2} \mathrm{yr}^{-1}\right)$ was somewhat higher than with the KtW model (Table 3). Consequently, a higher transfer efficiency between primary and secondary production is indicated by the modified KtW model: $T_{Z}=24.5 / 187=0.13$.

Secchi depth as a function of primary production

Fleming-Lehtinen \& Laamanen (2012) found that the Baltic Sea Secchi depth cannot be linked solely to phytoplankton biomass due to a high background light attenuation. We approximated the background light attenuation from 123 observations of the attenuation coefficient of downwelling irradiance $(K)$, chlorophyll (chl), and salinity (sal) made during 13 cruises (Haraldsson et al. 2013) in the Baltic Proper in 2009 and 2010 (Table 5). The reason for including salinity is that attenuation is known to be strongly affected by color dissolved organic matter (CDOM) originating from terrestrial and freshwater sources, and that light absorption is negatively linearly related to salinity due to the dilution effect, with high-salinity water having lower light absorption (Aarup et al. 1996, Højerslev et al. 1996, Aksnes et al. 2009). The regression analysis (Table 5) suggests a light attenuation of $0.64 \mathrm{~m}^{-1}$ of the Baltic Sea freshwater sources (i.e. for sal $=0$ and $\mathrm{chl}=0$ ), and further that a water column with salinity of 8 to 9 , which is

Table 4. Predation coefficients ( $\alpha$ in Appendix 1 ) of the modified 'Killing the Winner' model when a length scale of $50 \mathrm{~m}$ was assumed to represent the extension of the vertical habitat (see Appendix 1). The estimates were obtained by assuming steady state and solving Eq. A3 of Appendix 1 by the insertion of the total biomasses and the loss rates in Table 2, assuming all yields $(Y)$ equal to 0.1 , and that the vertical habitat of the fishes was reduced by $50 \%$ according to a primary production of $187 \mathrm{~g} \mathrm{C} \mathrm{m}^{-2} \mathrm{yr}^{-1}$ (Wasmund et al. 2001)

\begin{tabular}{|lccc|}
\hline & Symbol & Estimate & Unit \\
\hline $\begin{array}{l}\text { Mass entering zooplankton }(Z) \\
\text { Expressed per surface area }\end{array}$ & $P_{Z}$ & 6.3 & $\mathrm{Mt} \mathrm{C} \mathrm{yr}^{-1}$ \\
Predation coefficient of & & 24.5 & $\mathrm{~g} \mathrm{C} \mathrm{m}^{-2} \mathrm{yr}^{-1}$ \\
jellyfish $(J)$ & $\alpha_{J}$ & 2113 & $\mathrm{~m}^{3}\left(\mathrm{~g} \mathrm{C}^{-1} \mathrm{yr}^{-1}\right.$ \\
sprat/herring $(F)$ & $\alpha_{F}$ & 505 & $\mathrm{~m}^{3}\left(\mathrm{~g} \mathrm{C}^{-1} \mathrm{yr}^{-1}\right.$ \\
of cod $(C)$ & $\alpha_{C}$ & 161 & $\mathrm{~m}^{3}\left(\mathrm{~g} \mathrm{C}^{-1} \mathrm{yr}^{-1}\right.$ \\
\hline
\end{tabular}

Table 5. Relationship between the attenuation coefficient $(K)$ for downwelling irradiance (photosynthetically active radiation), chlorophyll, and salinity in the Baltic Sea. The coefficients were estimated according to the multiple regression analysis, $K=a+b \cdot \mathrm{chl}-c \cdot S$. The observations (n =123) are from stations with a salinity $<10$ obtained during cruises in the Baltic Proper from May 2009 to April 2010 (Haraldsson et al. 2013). The ranges of the values used in the analysis were $0.09-0.53 \mathrm{~m}^{-1}, 6.42-8.02$ and $0.2-5.8 \mathrm{mg} \mathrm{chl} \mathrm{l}^{-1}$ for $K$, salinity, and chlorophyll, respectively. The estimated multiple correlation coefficient $(r)$ was 0.50

\begin{tabular}{|lrcc|}
\hline Coefficient & Estimate & $95 \%$ CI & $\mathrm{p}$ \\
\hline Intercept, $a$ & 0.636 & 0.029 & $1.5 \times 10^{-4}$ \\
Chlorophyll, $b$ & -0.060 & 0.004 & $6.8 \times 10^{-3}$ \\
Salinity, $c$ & 0.020 & 0.001 & $3.7 \times 10^{-5}$ \\
\hline
\end{tabular}

devoid of chlorophyll, has a background attenuation of 0.1 to $0.16 \mathrm{~m}^{-1}$. Use of the relationship $S=1.44 / \mathrm{K}$ (Kirk 2011) indicates a background Secchi disk depth (i.e. for $\mathrm{chl}=0$ ) of the present Baltic Sea of 10 to $15 \mathrm{~m}$, which suggests that the Secchi depth of a water column devoid of primary production is about twice that of the current situation $(6 \mathrm{~m})$.

\section{RESULTS}

\section{Predictions from the KtW model}

We plotted the steady-state solutions as a function of eutrophication (Fig. 3) for the loss rates and predation coefficients in Tables 2 \& 3 . The degree of eutrophication was converted into units of primary production according to $T_{Z}=0.09$ (see Materials and Methods). For a primary production less than $32 \mathrm{~g} \mathrm{C}$ $\mathrm{m}^{-2} \mathrm{yr}^{-1}$ (marked with arrow 1 in Fig. 3), the KtW predicts that the mass entering the system is too low to sustain cod and jellyfish. Above this threshold, cod enters and increases with increased eutrophication until the next threshold is reached at a primary production of $91 \mathrm{~g} \mathrm{C} \mathrm{m}^{-2} \mathrm{yr}^{-1}$ (arrow 2). Here jellyfish enter, and further eutrophication leads to accumulation of jellyfish biomass, while the biomasses of the zooplankton and fishes remain unchanged. The present Baltic Sea (i.e. the observed biomasses of Table 2) is marked with arrow 3 at a primary production of $187 \mathrm{~g} \mathrm{C} \mathrm{m}^{-2} \mathrm{yr}^{-1}$ (Wasmund et al. 2001). 


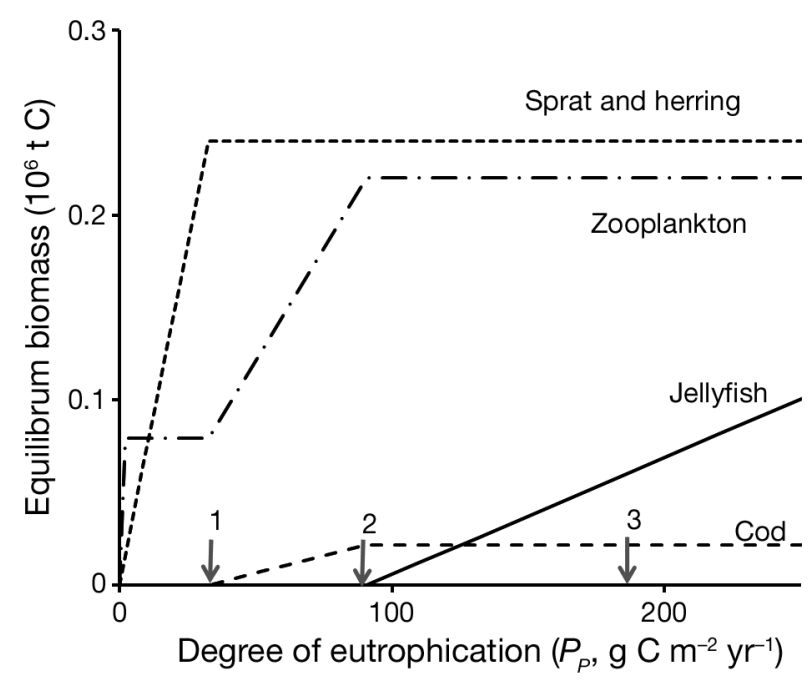

Fig. 3. Steady-state solution of the 'Killing the Winner' model as a function of eutrophication. Eutrophication is approximated by annual primary production by assuming a transfer efficiency of $T_{Z}=0.09$ between primary producers and zooplankton (see 'Materials and methods'). The solution is given for the loss rates and the predation coefficients given in Tables $2 \& 3$, respectively. Arrows: entry point of cod (1), jellyfish (2) and the current state of the Baltic Sea (3) which corresponds to a primary production of $187 \mathrm{~g} \mathrm{C} \mathrm{m}^{-2}$ $\mathrm{yr}^{-1}$ (Wasmund et al. 2001)

\section{Sensitivity}

The existence of the 2 thresholds (Eqs. 3 and 6 and arrows 1 and 2 in Fig. 3) is inherent to the KtW structure, but the estimated values of these thresholds are sensitive to errors in the coefficients of the model. From Table 6 it can be seen that the estimated threshold for jellyfish existence is increased from 91 to $149 \mathrm{~g} \mathrm{C} \mathrm{m}^{-2} \mathrm{yr}^{-1}$ for a doubling of the cod biomass, or of the loss rate estimate that was used in the analysis (Table 2). The highest sensitivity of the predicted threshold is seen for uncertainties in the coefficients of the fishes, while the coefficients concerning zooplankton and jellyfish do not affect the estimated threshold. This lack of sensitivity to the zooplankton and jellyfish coefficients is surprising. According to Eq. (3), the mortality of jellyfish does affect the threshold in the same way as cod mortality. However, a change in the jellyfish mortality also affects the predation coefficient of jellyfish (also in Eq. 3) that cancels out the effect on the calculated threshold. Nevertheless, we emphasize that our Baltic Sea application serves the purpose of illustrating the general aspects of the KtW predictions rather than providing accurate estimates.
Table 6. Sensitivity of a 'Killing the Winner' prediction for changes in biomasses and loss rates of the different groups. Numbers are the calculated degree of eutrophication ( $\mathrm{g} \mathrm{C}$ $\mathrm{m}^{-2} \mathrm{yr}^{-1}$ ) required for jellyfish existence (i.e. threshold provided by Eq. 3) when the specified input parameters were 50 and $200 \%$ of the values used in the analysis (Table 2). The values used in the analysis gave an estimate of $91 \mathrm{~g} \mathrm{C}$ $\mathrm{m}^{-2} \mathrm{yr}^{-1}$ (see 'Results')

\begin{tabular}{|lcr|}
\hline Parameter & $50 \%$ & $200 \%$ \\
\hline Zooplankton biomass & 91 & 91 \\
Jellyfish biomass & 91 & 91 \\
Sprat and herring biomass & 74 & 123 \\
Cod biomass & 62 & 149 \\
Jellyfish loss rate & 91 & 91 \\
Sprat and herring loss rate & 74 & 123 \\
Cod loss rate & 62 & 149 \\
\hline
\end{tabular}

Predicted effects of fishery

The 2 coefficients $\delta_{F}$ and $\delta_{C}$ are the fishery mortalities of sprat and herring or cod, respectively, and the predicted effects from fishery can be assessed directly from the equations. From $F^{*}=\delta_{C} / Y_{C} a_{C}$ (Eq. 2c), we see that the consequence of increased cod fishery is a linear increase in $F^{*}$ (sprat and herring) at the expense of jellyfish according to $J^{*}=A-$ $\delta_{C} B$ ( $A$ and $B$ are lumped coefficients of Eq. 2b). Decreased cod fishery leads to the opposite situation where the sprat and herring stocks decrease while that of the jellyfish increases. As noted above, and seen from Eq. (3), a decreased cod fishery also decreases the eutrophication threshold for jellyfish entry to the system. Thus a general KtW implication is that jellyfish abundance is stimulated by eutrophication, but that this effect is counteracted by fishery of the top predator in the KtW structure.

Decreased sprat and herring fishery results, not surprisingly, in increased cod according to $C^{*}=a_{C}{ }^{-1}$ $\left(A-\delta_{F}\right)$ (Eq. 2d, where $\left.A=Y_{F} a_{F} \delta_{J} / Y_{J} a_{J}\right)$ and vice versa. More surprising, according to Eq. (2b), jellyfish abundance is unaffected by changes in fishery on its competitor. This insensitivity to fishing intensity might appear counterintuitive and is discussed below.

\section{Predictions from the modified KtW model}

The assumption that the habitat of the fishes is gradually reduced with increased eutrophication leads to a 2-sided effect of eutrophication with an optimal degree of eutrophication for which the fish biomass is maximal (Fig. 4). Initially, the results are 
similar to the predictions of the basic KtW model (Fig. 3), with an increase in the sprat and herring biomass as a function of increased eutrophication. In this phase the stimulating effect of increased mass (i.e. primary production) that enters the system overrides the negative effect of a shrinking vertical habitat. At the entry point of cod (arrow 1 in Fig. 4), however, the combined effect of habitat loss and cod predation results in decreased sprat and herring biomass as eutrophication increases further. Cod reaches the maximal biomass at the entry point of jellyfish (arrow 2 in Fig. 4), and the decrease thereafter is also caused by habitat deterioration. For the modified KtW there is a steeper increase $(\sim 50 \%)$ in jellyfish biomass with increased eutrophication than for the basic KtW which is associated with the concurrent decline in the fish stocks in the modified KtW.

The maximal biomass of sprat and herring in the modified KtW (Fig. 4) is about twice the plateau reached in the basic KtW (Fig. 3). This difference is due to methodological differences in the estimation of the predation coefficients. The biomasses for the current Baltic Sea (Table 2), which is indicated by arrow 3 in Figs. 3 \& 4, are the same in the 2 scenarios. Because the predation coefficients are estimated from the values in Table 2, and the modified KtW assumes $50 \%$ habitat loss for this situation, the biomass becomes higher at a larger habitat size in the case of the modified KtW model.

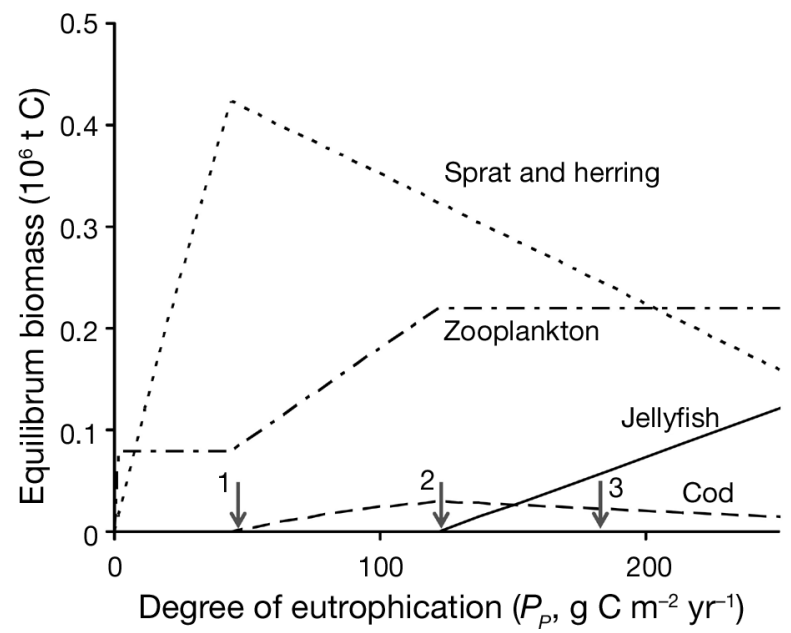

Fig. 4. Steady-state solution of the modified 'Killing the Winner' model as a function of eutrophication. Eutrophication is approximated by annual primary production by assuming a transfer efficiency of $T_{Z}=0.13$ between primary producers and zooplankton (see 'Materials and methods'). The solution is given for the loss rates and the predation coefficients given in Tables $2 \& 4$, respectively. Arrows: entry point of cod (1), jellyfish (2), and the current state of the Baltic Sea (3), which corresponds to a primary production of $187 \mathrm{~g} \mathrm{C}$ $\mathrm{m}^{-2} \mathrm{yr}^{-1}$ (Wasmund et al. 2001)
In Fig. 5, the results of the modified KtW are plotted as a function of Secchi depth instead of primary production. Here we see that the zooplanktivorous fish biomass (sprat and herring) increases linearly with increased water clarity (i.e. deeper Secchi depth) until a point where the diminishing primary production cannot sustain the zooplanktivorous biomass anymore and the biomass collapses accordingly. The same pattern is indicated for cod.

\section{DISCUSSION}

The extensive changes in the Baltic Sea (Table 1) make environmental analyses particularly challenging. Climate-related changes such as increased sea surface temperature have been reported (Fonselius \& Valderrama 2003, Mackenzie et al. 2007), and the Baltic Sea is considered one of the quickest-warming seas worldwide (Belkin 2009). Detailed mechanistic (Österblom et al. 2007) and statistical (Casini et al. 2008, 2009, Llope et al. 2011) dynamic models obviously capture much more of the complexity of the Baltic Sea ecosystem than the steady-state KtW model. The role of jellyfish has not been explicitly addressed in such analyses, which is likely due to lack of jellyfish time series and lack of reports of mass occurrences similar to those occurrences that have been reported for e.g. the Black Sea (Llope et al. 2011).

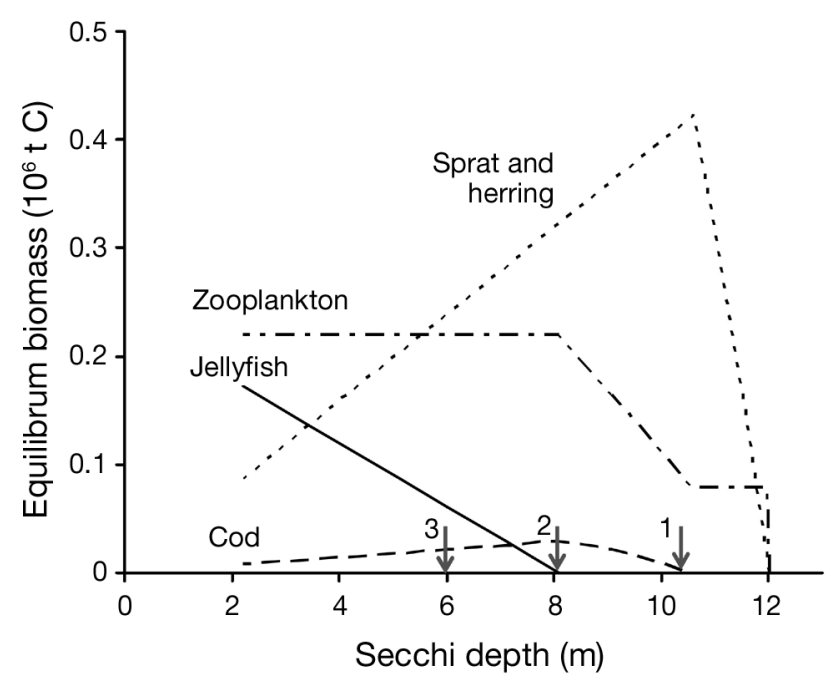

Fig. 5. Steady-state solution of the modified 'Killing the Winner' model given as a function of Secchi depth instead of primary production as in Fig 4. Arrows: entry point of cod (1), jellyfish (2), and the current state of the Baltic Sea (3), which corresponds to a Secchi depth of $6 \mathrm{~m}$ (see 'Materials and methods') 
Our Baltic Sea application targets a particular environmental aspect, i.e. eutrophication and water clarity, and ignores others such as warming, hypoxia, and toxic pollutants. We acknowledge this limitation of our study, and our Baltic Sea application first of all serves the purpose of illustrating what we think are valuable insights of the KtW model for the jellyfishfish system. The KtW model has its main advantage in being generic, transparent, and analytically tractable. Despite its simplicity, the KtW model is known to capture many aspects of the relationship between microbial organisms (Winter et al. 2010). KtW features such as mass balance, competition for a common resource, and tradeoff conflicts associated with investments in defense and resource acquisition are crucial, not only for the microbial community, but for organisms in general.

A fundamental assumption underlying the KtW predictions in Figs. $3 \& 4$ is the framing of jellyfish as a defense specialist (Fig. 1). If this assumption is not warranted, the KtW does not apply. The crucial point is that the mortality coefficient of jellyfish can be specified by a coefficient that is not seriously affected by the dynamics of a top predator. This constant mortality coefficient is in contrast to that of the competition specialist, which indeed is affected by the dynamics of the top predator (Fig. 2).

The KtW model provides expectations, and potentially insights, that may appear surprising. It predicts a threshold criterion for the presence of jellyfish (i.e. the defense specialist) that connects to a particular degree of eutrophication, which is modified by e.g. the mortality of the top predator. Increase in eutrophication above this threshold results in more jellyfish, but no further increase in its fish competitor (competition specialist) or the top predator (Figs. 3 \& 4). These predictions must be understood as emergent properties of the generic KtW structure (Fig. 1). Other predictions appear more trivial, e.g. that decreased fishery mortality of the top predator (cod) provides increased jellyfish abundance. Intuitively, this expectation can be linked to reduced food competition since the biomass of the competition specialist (sprat and herring) is suppressed due to higher predation from an elevated cod stock. The prediction that the abundance of jellyfish is unaffected by sprat and herring fishery, however, appears counterintuitive. Intuitively, increased sprat and herring fishery will lower these stocks, at least for a period of time, due to delays associated with maturation and reproduction, and thereby leave more zooplankton for jellyfish growth. It is not obvious, however, whether such time delays would facilitate a permanent or a temporary rise in jellyfish biomass. In any case, an important limitation in our analysis is that the steadystate solution cannot account for such temporal dynamics.

The prediction that there are no negative effects of an ever increasing eutrophication (i.e. Fig. 3) appears unsound. This expectation is likely to be less realistic for fish than for the microbial communities to which KtW has primarily been applied (Winter et al. 2010), and it may be more important to address a 2-sided effect of eutrophication for higher than for lower trophic levels.

\section{Two-sided effect of eutrophication}

The assumption that fish habitat is affected negatively by decreasing water clarity results in a linear increase in fish biomass with increasing Secchi depth as long as the production of the system is sufficient to support such increase (i.e. up to arrow 1 for sprat and herring in Fig. 5). Evidence of such a linear relationship between fish biomass and Secchi depth has been reported for the Black Sea (Aksnes 2007). In that study, Secchi depth was a surprisingly accurate predictor of fish biomass over a $30 \mathrm{yr}$ time series, and a Secchi depth shoaling of $1 \mathrm{~m}$ corresponded to a decrease of about 100000 t of fish. Extrapolation suggested a critical Secchi depth of 4 to $5 \mathrm{~m}$ where the fish biomass became 0. No such critical Secchi depth, other than 0 m, was assumed in Fig. 5. If such critical water clarity is introduced to the model, a new threshold will emerge. Water clarity lower than the critical value would allow the presence of jellyfish and zooplankton only (not shown). Such an effect of water clarity might be a matter of future concern since CDOM already makes a substantial contribution to the relatively low water clarity of the Baltic Sea (Fleming-Lehtinen \& Laamanen 2012), and a substantial increase in CDOM loads is expected due to increased warming and precipitation (Larsen et al. 2011)

Unfortunately, lack of time series of jellyfish prohibits a close inspection of how the KtW model compares with the development in the Baltic Sea. The study of Möller (1980) indicates a jellyfish biomass of $24 \mathrm{Mt}$ wet weight (WW) in 1978 (Table 7). This number is less than the estimate for the current situation (61 Mt WW, Table 2), but these estimates do not allow a robust statistical comparison. In Table 7 we have also provided the average biomasses of zooplankton, sprat and herring, and cod in the period 1974 to 1979 , which can be compared with the aver- 
Table 7. Biomasses (mean $\pm \mathrm{SD}$; wet weight in $\mathrm{Mt}$ ) in the Baltic Sea for the period 1974 to 1979, except for jellyfish, which represent sampling in September 1978 (the biomass of jellyfish in Table 2 also represents September)

$\left.\begin{array}{|lcl|}\hline \text { Group } & \text { Biomass } & \text { Source } \\ \hline \text { Zooplankton }(Z) & 4.2 \pm 0.8 & \text { Casini et al. (2008) } \\ \text { Jellyfish }(J) & 24.2 & \text { Möller (1980) } \\ \begin{array}{l}\text { Sprat and } \\ \text { herring }(F)\end{array} & 4.02 \pm 0.23 \\ \text { Cod }(C) & 0.73 \pm 0.18\end{array}\right\} \begin{gathered}\text { Swedish Agency for } \\ \text { Marine and Water } \\ \text { Management (2010) }\end{gathered}$

ages for the period 2000 to 2009 (Table 2). It can be concluded that the fish stocks were significantly higher in the early period while the zooplankton biomass estimates were similar. Hence, the direction of the changes in all 4 groups is consistent with the expectation of the modified KtW (Figs. 4 \& 5) if Secchi depth was shallower in the late than in the early period. The study of Fleming-Lehtinen \& Laamanen (2012, their Fig. 3) indeed suggests a 1 to 2 m reduction in Secchi depth for most of the sub-basins in the Baltic Sea since the 1970s.

According to the KtW predictions, it might be speculated that the current high cod fishery (Table 2) contributes to a suppression of the Baltic Sea jellyfish biomass, and that a shift towards more cod, and less sprat and herring, would lead to increased jellyfish abundance. Nevertheless, the KtW expectations presented in our study obviously need to be confronted with observations in future studies. Due to a general lack of reliable time series for jellyfish, future studies could involve 'space for time' sampling, i.e. sampling from different locations that reflect a gradient in eutrophication and water clarity.

Acknowledgements. We thank M. Casini for providing zooplankton biomass data. This work is a contribution to Baltic Zooplankton Cascades (BAZOOCA) funded by Baltic Organizations Network for funding Science, European Economic Interest Grouping (BONUS, EEIG), and the Swedish Research Council for Environment, Agricultural Sciences, and Spatial Planning (FORMAS) project 210-2008-1882. We received additional support from the EU-ERC project MINOS (ref no 250254) and the Norwegian Research Council (project no 196444).

\section{LITERATURE CITED}

Aarup T, Holt N, Højerslev NK (1996) Optical measurements in the North Sea-Baltic Sea transition zone. 2. Water mass classification along the Jutland west coast from salinity and spectral irradiance measurements. Cont Shelf Res 16:1343-1353
Acuña JL, López-Urrutia Á, Colin S (2011) Faking giants: the evolution of high prey clearance rates in jellyfishes. Science 333:1627-1629

> Aksnes DL (2007) Evidence for visual constraints in large marine fish stocks. Limnol Oceanogr 52:198-203

Aksnes DL, Utne ACW (1997) A revised model of visual range in fish. Sarsia 82:137-147

Aksnes DL, Dupont N, Staby A, Fiksen Ø, Kaartvedt S, Aure J (2009) Coastal water darkening and implications for mesopelagic regime shifts in Norwegian fjords. Mar Ecol Prog Ser 387:39-49

Alheit J, Möllmann C, Dutz J, Kornilovs G, Loewe P, Mohrholz V, Wasmund N (2005) Synchronous ecological regime shifts in the central Baltic and the North Sea in the late 1980s. ICES J Mar Sci 62:1205-1215

Andersen $\mathrm{JH}$, Axe $\mathrm{P}$, Backer $\mathrm{H}$, Carstensen $\mathrm{J}$ and others (2011) Getting the measure of eutrophication in the Baltic sea: towards improved assessment principles and methods. Biogeochemistry 106:137-156

Arrhenius F, Hansson S (1993) Food consumption of larval, young and adult herring and sprat in the Baltic Sea. Mar Ecol Prog Ser 96:125-137

> Backer H, Leppanen JM (2008) The HELCOM system of a vision, strategic goals and ecological objectives: implementing an ecosystem approach to the management of human activities in the Baltic Sea. Aquat Conserv 18: 321-334

> Barz K, Hirche HJ (2005) Seasonal development of scyphozoan medusae and the predatory impact of Aurelia aurita on the zooplankton community in the Bornholm basin (central Baltic Sea). Mar Biol 147:465-476

Belkin IM (2009) Rapid warming of large marine ecosystems. Prog Oceanogr 81:207-213

Brodeur RD, Sugisaki H, Hunt GL Jr (2002) Increases in jellyfish biomass in the Bering Sea: implications for the ecosystem. Mar Ecol Prog Ser 233:89-103

Brotz LL, Cheung WWL, Kleisner K, Pakhomov E, Pauly D (2012) Increasing jellyfish populations: trends in Large Marine Ecosystems. Hydrobiologia 690:3-20

Casini M, Lövgren J, Hjelm J, Cardinale M, Molinero JC, Kornilovs G (2008) Multi-level trophic cascades in a heavily exploited open marine ecosystem. Proc R Soc Lond B Biol Sci 275:1793-1801

Casini M, Hjelm J, Molinero JC, Lövgren J and others (2009) Trophic cascades promote threshold-like shifts in pelagic marine ecosystems. Proc Natl Acad Sci USA 106:197-202

Condon RH, Graham WM, Duarte CM, Pitt KA and others (2012) Questioning the rise of gelatinous zooplankton in the world's oceans. Bioscience 62:160-169

> Daskalov GM, Grishin AN, Rodionov S, Mihneva V (2007) Trophic cascades triggered by overfishing reveal possible mechanisms of ecosystem regime shifts. Proc Natl Acad Sci USA 104:10518-10523

> Decker MB, Breitburg DL, Purcell JE (2004) Effects of low dissolved oxygen on zooplankton predation by the ctenophore Mnemiopsis leidyi. Mar Ecol Prog Ser 280: 163-172

> Diaz RJ, Rosenberg R (2008) Spreading dead zones and consequences for marine ecosystems. Science 321:926-929

> Dupont N, Aksnes DL (2010) Simulation of optically conditioned retention and mass occurrences of Periphylla periphylla. J Plankton Res 32:773-783

Eggers DM (1977) Nature of prey selection by planktivorous fish. Ecology 58:46-59 
Elmgren R (2001) Understanding human impact on the Baltic ecosystem: changing views in recent decades. Ambio 30:222-231

Faasse MA, Bayha KM (2006) The ctenophore Mnemiopsis leidyi A. Agassiz 1865 in coastal waters of the Netherlands: an unrecognized invasion? Aquat Invasions 1: $270-277$

Finni T, Kononen K, Olsonen R, Wallström K (2001) The history of cyanobacterial blooms in the Baltic Sea. Ambio 30:172-178

Fleming-Lehtinen V, Laamanen M (2012) Long-term changes in Secchi depth and the role of phytoplankton in explaining light attenuation in the Baltic Sea. Estuar Coast Shelf Sci 102-103:1-10

Fonselius S, Valderrama J (2003) One hundred years of hydrographic measurements in the Baltic Sea. J Sea Res 49:229-241

Graham WM, Bayha KM (2007) Biological invasions by marine jellyfish. Ecol Stud 193:239-255

Haraldsson M, Hansson L (2011) New knowledge about the spatial and temporal changes of gelatinous zooplankton in the Baltic Sea. Scientific report from the 'Baltic Zooplankton Cascades (BAZOOCA)'. Report no. 2. Working package 1. University of Gothenburg, Gothenburg

Haraldsson M, Jaspers C, Tiselius P, Aksnes DL, Andersen T, Titelman J (2013) Environmental constraints of the invasive Mnemiopsis leidyi in Scandinavian waters. Limnol Oceanogr 58:37-48

Højerslev NK, Holt N, Aarup T (1996) Optical measurements in the North Sea-Baltic Sea transition zone. 1. On the origin of the deep water in the Kattegat. Cont Shelf Res 16: 1329-1342

> Javidpour J, Sommer U, Shiganova TA (2006) First record of Mnemiopsis leidyi A. Agassiz 1865 in the Baltic Sea. Aquat Invasions 1:299-302

Johnsen S (2012) The optics of life. Princeton University Press, Princeton, NJ

Kirk JTO (2011) Light and photosynthesis in aquatic ecosystems. Cambridge University Press, Cambridge

> Larsen S, Andersen T, Hessen DO (2011) Climate change predicted to cause severe increase of organic carbon in lakes. Glob Change Biol 17:1186-1192

> Leppäkoski E, Gollasch S, Gruszka P, Ojaveer H, Olenin S, Panov V (2002) The Baltic - a sea of invaders. Can J Fish Aquat Sci 59:1175-1188

> Lester NP, Dextrase AJ, Kushneriuk RS, Rawson MR, Ryan PA (2004) Light and temperature: key factors affecting walleye abundance and production. Trans Am Fish Soc 133:588-605

> Llope M, Daskalov GM, Rouyer TA, Mihneva V, Chan KS, Grishin AN, Stenseth NC (2011) Overfishing of top predators eroded the resilience of the Black Sea system regardless of the climate and anthropogenic conditions. Glob Change Biol 17:1251-1265

> Lo WT, Purcell JE, Hung JJ, Su HM, Hsu PK (2008) Enhancement of jellyfish (Aurelia aurita) populations by extensive aquaculture rafts in a coastal lagoon in Taiwan. ICES J Mar Sci 65:453-461

> Loehle C (1983) Evaluation of theories and calculation tools in ecology. Ecol Model 19:239-247

> Lynam CP, Gibbons MJ, Axelsen BE, Sparks CAJ, Coetzee J, Heywood BG, Brierley AS (2006) Jellyfish overtake fish in a heavily fished ecosystem. Curr Biol 16: R492-R493

> Lynam CP, Lilley MKS, Bastian T, Doyle TK, Beggs SE, Hays
GC (2011) Have jellyfish in the Irish Sea benefited from climate change and overfishing? Glob Change Biol 17: 767-782

Mackenzie BR, Schiedek D (2007) Daily ocean monitoring since the 1860s shows record warming of northern European Seas. Glob Change Biol 13:1335-1347

> Mackenzie BR, Gislason H, Möllmann C, Köster FW (2007) Impact of 21st century climate change on the Baltic Sea fish community and fisheries. Glob Change Biol 13: 1348-1367

Meier HEM, Andersson HC, Eilola K, Gustafsson BG and others (2011) Hypoxia in future climates: a model ensemble study for the Baltic Sea. Geophys Res Lett 38:L24608, doi:10.1029/2011GL049929

Möller H (1980) A summer survey of large zooplankton, particularly scyphomedusae, in North Sea and Baltic. Meeresforschung 28:61-68

> Oguz T, Salihoglu B, Fach B (2008) A coupled planktonanchovy population dynamics model assessing nonlinear controls of anchovy and gelatinous biomass in the Black Sea. Mar Ecol Prog Ser 369:229-256

Olli K, Klais R, Tamminen T, Ptacnik R, Andersen T (2011) Long term changes in the Baltic Sea phytoplankton community. Boreal Environ Res 16:3-14

Österblom H, Hansson S, Larsson U, Hjerne O, Wulff F, Elmgren R, Folke C (2007) Human-induced trophic cascades and ecological regime shifts in the Baltic Sea. Ecosystems 10:877-889

Parsons TR, Lalli CM (2002) Jellyfish population explosions: revisiting a hypothesis of possible causes. Mer (Tokyo) 40:111-121

Parsons TR, Maita Y, Lalli CM (1992) A manual of chemical and biological methods for seawater analysis. Pergamon, Oxford

> Preisendorfer RW (1986) Secchi disk science - visual optics of natural waters. Limnol Oceanogr 31:909-926

> Purcell JE (2012) Jellyfish and ctenophore blooms coincide with human proliferations and perturbations. Annu Rev Mar Sci 4:209-235

Purcell JE, Uye S, Lo WT (2007) Anthropogenic causes of jellyfish blooms and their direct consequences for humans: a review. Mar Ecol Prog Ser 350:153-174

> Richardson AJ, Gibbons MJ (2008) Are jellyfish increasing in response to ocean acidification? Limnol Oceanogr 53: 2040-2045

Richardson AJ, Bakun A, Hays GC, Gibbons MJ (2009) The jellyfish joyride: causes, consequences and management responses to a more gelatinous future. Trends Ecol Evol $24: 312-322$

Ruiz J, Prieto L, Astorga D (2012) A model for temperature control of jellyfish (Cotylorhiza tuberculata) outbreaks: a causal analysis in a Mediterranean coastal lagoon. Ecol Model 233:59-69

Sanden P, Håkansson B (1996) Long-term trends in Secchi depth in the Baltic Sea. Limnol Oceanogr 41:346-351

> Savchuk OP, Wulff F, Hille S, Humborg C, Pollehne F (2008) The Baltic Sea a century ago-a reconstruction from model simulations, verified by observations. J Mar Syst 74:485-494

> Schneider G (1988) Chemical composition and biomass parameters of the common jellyfish Aurelia aurita. Helgol Meersunters 42:319-327

Sørnes TA, Aksnes DL (2004) Predation efficiency in visual and tactile zooplanktivores. Limnol Oceanogr 49:69-75 Sørnes TA, Aksnes DL, Båmstedt U, Youngbluth MJ (2007) 
Causes for mass occurrences of the jellyfish Periphylla periphylla: a hypothesis that involves optically conditioned retention. J Plankton Res 29:157-167

Sparholt H (1994) Fish species interactions in the Baltic Sea. Dana 10:131-162

Struck U, Emeis KC, Voss M, Christiansen C, Kunzendorf H (2000) Records of southern and central Baltic Sea eutrophication in $\delta^{13} \mathrm{C}$ and $\delta^{15} \mathrm{~N}$ of sedimentary organic matter. Mar Geol 164:157-171

Swedish Agency for Marine and Water Management (2010) Fiskebestånd och miljö i hav och sötvatten. Resurs- och miljööversikt 2010. Fiskeriverket. Available at www.havochvatten.se

Tendal OS, Jensen KR, Riisgård HU (2007) Invasive ctenophore Mnemiopsis leidyi widely distributed in Danish waters. Aquat Invasions 2:455-460

Thingstad TF, Strand E, Larsen A (2010) Stepwise building of plankton functional type (PFT) models: a feasible route to complex models? Prog Oceanogr 84:6-15

> Thuesen EV, Rutherford LD, Brommer PL, Garrison K, Gutowska MA, Towanda T (2005) Intragel oxygen pro- motes hypoxia tolerance of scyphomedusae. J Exp Biol 208:2475-2482

- Thurow F (1997) Estimation of the total fish biomass in the Baltic Sea during the 20th century. ICES J Mar Sci 54: 444-461

Wasmund N, Andrushaitis A, Lysiak-Pastuszak E, MüllerKarulis B and others (2001) Trophic status of the southeastern Baltic Sea: a comparison of coastal and open areas. Estuar Coast Shelf Sci 53:849-864

> Wasmund N, Göbel J, von Bodungen B (2008) 100-yearschanges in the phytoplankton community of Kiel Bight (Baltic Sea). J Mar Syst 73:300-322

- Weisse T, Gomoiu MT (2000) Biomass and size structure of the scyphomedusa Aurelia aurita in the northwestern Black Sea during spring and summer. J Plankton Res 22: 223-239

Winter C, Bouvier T, Weinbauer MG, Thingstad TF (2010) Trade-offs between competition and defense specialists among unicellular planktonic organisms: the 'Killing the Winner' hypothesis revisited. Microbiol Mol Biol Rev 74: $42-57$ 
Appendix 1. Calculations of habitat volumes and their incorportaion into the modified KtW model

Here we introduce habitat volumes in the KtW model. We first express the system of equations in terms of biomass densities $\left(\mathrm{g} \mathrm{C} \mathrm{m}^{-3}\right)$, indicated by lower case symbols, instead of total biomasses:

$$
\begin{aligned}
& \frac{\mathrm{d} z}{\mathrm{~d} t}=p_{Z}-\alpha_{F} z f-\alpha_{J} z j \\
& \frac{\mathrm{d} j}{\mathrm{~d} t}=Y_{J} \alpha_{J} z j-\delta_{J} j \\
& \frac{\mathrm{d} f}{\mathrm{~d} t}=Y_{F} \alpha_{F} z f-\alpha_{C} c f-\delta_{F} f \\
& \frac{\mathrm{d} C}{\mathrm{~d} t}=Y_{C} \alpha_{C} f C-\delta_{C} C
\end{aligned}
$$

The biomass densities relate to the total biomasses (g C) according to $z=Z / V_{Z,} j=J / V_{J}, f=F / V_{F}, C=C / V_{C}$, where $V$ is the respective habitat volume. We also have the rate $p_{Z}=$ $P_{Z} / V_{Z}$. A habitat volume of group $x$ is $V_{X}=A H_{X}$ where $A$ is $258310 \mathrm{~km}^{2}$ (the surface area of the Baltic Proper and the Gulf of Finland), and the extension of the vertical habitat $H_{x}$ was set equal to the upper $50 \mathrm{~m}$ for the zooplankton and jellyfish and also for the 2 fish groups in the case of no visual constraints. As explained in the main text, visual constraints were assumed for the fishes so that $H_{F}$ and $H_{C}$ were reduced with $2.7 \%$ for each $10 \mathrm{~g} \mathrm{C} \mathrm{m}^{-2} \mathrm{yr}^{-1}$ rise in primary production.

We now express the equations in terms of total biomasses:

$$
\begin{aligned}
\frac{\mathrm{d} Z}{\mathrm{~d} t} & =P_{Z}-\frac{\alpha_{F}}{V_{F}} Z F-\frac{\alpha_{J}}{V_{J}} Z J \\
\frac{\mathrm{d} J}{\mathrm{~d} t} & =Y_{J} \frac{\alpha_{J}}{V_{Z}} Z J-\delta_{J} J \\
\frac{\mathrm{d} F}{\mathrm{~d} t} & =Y_{F} \frac{\alpha_{F}}{V_{Z}} Z F-\frac{\alpha_{C}}{V_{C}} F C-\delta_{F} F \\
\frac{\mathrm{d} C}{\mathrm{~d} t} & =Y_{C} \frac{\alpha_{C}}{V_{F}} F C-\delta_{C} C
\end{aligned}
$$

Note that the predation coefficients indicated with $a$ in Fig. 2 are different from $\alpha$ specified here. The $\alpha$ values correspond to 'clearance rates' and have units of $\mathrm{m}^{3}(\mathrm{~g} \mathrm{C})^{-1}$ $\mathrm{yr}^{-1}$. These rates are affected by the choice of a $50 \mathrm{~m}$ vertical habitat above, but it should be noted that the solution on how equilibrium biomasses distribute as a function of the degree of eutrophication (Fig. 4) is not affected.

Solving for steady state yields the following equilibrium biomasses:

$$
\begin{aligned}
Z^{*} & =V_{Z} \frac{\delta_{J}}{Y_{J} \alpha_{J}} \\
J^{*} & =V_{J}\left(\frac{Y_{J} P_{Z}}{V_{Z} \delta_{J}}-\frac{\alpha_{F} \delta_{C}}{Y_{C} \alpha_{C} \alpha_{J}}\right) \\
F^{*} & =V_{F} \frac{\delta_{C}}{Y_{C} \alpha_{C}} \\
C^{*} & =V_{C}\left(\frac{Y_{F} \alpha_{F} \delta_{J}}{Y_{J} \alpha_{J} \alpha_{C}}-\frac{\delta_{F}}{\alpha_{C}}\right)
\end{aligned}
$$

Here we see that jellyfish existence (i.e. positive values of $\left.J^{*}\right)$ requires that the degree of eutrophication $\left(P_{Z}\right)$ exceeds a threshold value:

$$
P_{Z}>V_{Z} \frac{\alpha_{F} \delta_{C} \delta_{J}}{Y_{C} Y_{J} \alpha_{C} \alpha_{J}}
$$

For $P_{Z}$ less than this quantity, the system of equations reduces to

$$
\begin{aligned}
\frac{\mathrm{d} Z}{\mathrm{~d} t} & =P_{Z}-\frac{\alpha_{F}}{V_{F}} Z F \\
\frac{\mathrm{d} F}{\mathrm{~d} t} & =Y_{F} \frac{\alpha_{F}}{V_{Z}} Z F-\frac{\alpha_{C}}{V_{C}} C F-\delta_{F} F \\
\frac{\mathrm{d} C}{\mathrm{~d} t} & =Y_{C} \frac{\alpha_{C}}{V_{F}} F C-\delta_{C} C
\end{aligned}
$$

With the steady-state solution

$$
\begin{aligned}
Z^{*} & =P_{Z} \frac{Y_{C} \alpha_{C}}{\alpha_{F} \delta_{C}} \\
F^{*} & =V_{F} \frac{\delta_{C}}{Y_{C} \alpha_{C}} \\
C^{*} & =V_{C}\left(\frac{P_{Z} Y_{F} Y_{C}}{V_{Z} \delta_{C}}-\frac{\delta_{F}}{\alpha_{C}}\right)
\end{aligned}
$$

We see that cod existence (i.e. positive values of $C^{*}$ ) requires that the degree of eutrophication exceeds a threshold value:

$$
P_{Z}>V_{Z} \frac{\delta_{F} \delta_{C}}{Y_{F} Y_{C} \alpha_{C}}
$$

For $P_{Z}$ less than this quantity, the system of equations reduces to

$$
\begin{aligned}
& \frac{\mathrm{d} Z}{\mathrm{~d} t}=P_{Z}-\frac{\alpha_{F}}{V_{F}} Z F \\
& \frac{\mathrm{d} F}{\mathrm{~d} t}=Y_{F}-\frac{\alpha_{F}}{V_{Z}} Z F-\delta_{F} F
\end{aligned}
$$

With the steady-state solution

$$
\begin{aligned}
Z^{*} & =V_{Z} \frac{\delta_{F}}{Y_{F} \alpha_{F}} \\
F^{*} & =V_{F} \frac{P_{Z} Y_{F}}{V_{Z} \delta_{F}}
\end{aligned}
$$

